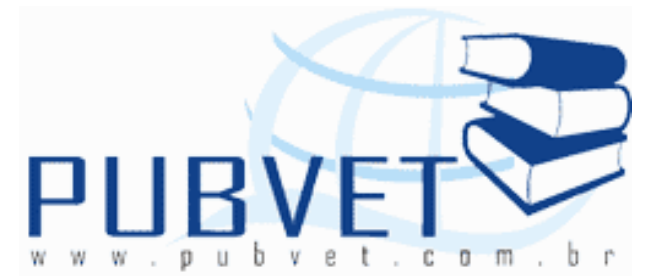

PUBVET, Publicações em Medicina Veterinária e Zootecnia.

\title{
Produção de bovinos de corte em pastagem de estação quente no Sul do Brasil - uma revisão
}

Milene Puntel Osmari ${ }^{1}$, Flânia Monego Argenta ${ }^{2}$, Perla Cordeiro de Paula ${ }^{2}$, Dari Celestino Alves Filho ${ }^{3}$, Ivan Luiz Brondani ${ }^{3}$

${ }^{1}$ Doutorado em Zootecnia - Universidade Estadual de Maringá

${ }^{2}$ Mestrado em Zootecnia - Universidade Federal de Santa Maria

3 Professor Universidade Federal de Santa Maria

\section{Resumo}

A base forrageira do Rio Grande do Sul durante o verão é a pastagem natural. Esta por sua vez pode proporcionar baixos ganhos médios diários, influenciando o sistema de criação, atrasando o entoure das novilhas, e proporcionando elevada idade de abate dos novilhos. A utilização de pastagens tropicais é uma ferramenta que pode ser utilizada pelos produtores para aumentar a eficiência do sistema de criação bovina. No entanto, quando se trata de acasalamento de novilhas, as forrageiras tropicais podem não ser suficientes para proporcionar escore de condição corporal desejável para assegurar o sucesso do acasalamento, sendo necessária utilização de suplementos. Contudo, o objetivo da revisão bibliográfica é descrever os principais resultados obtidos com a utilização de pastagens tropicais na região sul do Brasil, bem como discutir estratégias de manejo que favoreçam a máxima utilização destas forragens.

Palavras-chave: entoure de novilhas, pastagens tropicais, recria de bovinos 


\section{Cattle breeding in summer grassland in southern Brazil - a review}

\section{Abstract}

The natural grasslands are the main forage of Rio Grande do Sul in the Summer. But, it can provide small average daily gain, acting on the raise system, retarding the heifer's mat and proportion rise of age the bullock's killing. The tropical grasslands are the tool that may be utilized by creators to raise the efficiency of the raise cattle system. However, in the heifers couple, the tropical forage can't be enough to provide desirables body conditions to affirm the couple's success. Then, the use of supplementation may be another useful tool. Although, the objective of this paper is describe the most important results of the use of tropical grasslands in southern Brazil, and discuss strategies of management to the maximum utilization of these forages.

Keywords: mat heifers, tropical grasslands, cattle breeding

\section{Introdução}

No Rio Grande do Sul, durante o verão, a utilização da pastagem nativa representa a base forrageira para a produção de bovinos de corte, sendo que em categorias menos exigentes, como vacas de descarte, pode proporcionar ganhos de peso médios diários (GMD) satisfatórios.

A utilização exclusiva do campo nativo como fonte de nutrientes para ciclos completos de criação bovina pode limitar a produtividade do sistema, devido à elevada idade de entoure das novilhas; dificuldade de repetição de cria na estação de monta seguinte, acarretando em baixos índices de natalidade; além de elevada idade de abate dos novilhos.

Durante o verão as pastagens cultivadas são alternativas para produzir uma alimentação de melhor qualidade do que a pastagem nativa, possibilitando melhorar o desempenho dos animais (AITA, 1995; MÍsSIO et al., 2006; OSMARI, 2010; GUASSO et al., 2011). 
Para a escolha de uma forrageira deve-se considerar sua qualidade e nesse particular, o consumo e a digestibilidade, além do propósito e a categoria animal utilizada. Contudo, técnicas adequadas de manejo de pastagem devem ser empregadas, a fim de evitarmos sua degradação e, consequentemente, erosões no solo.

Existe uma tendência atual em formar pastagens para gado de corte com brachiarão (Brachiaria brizantha) em grande parte do Brasil e com espécies do gênero Panicum em regiões mais quentes. No entanto, dados de desempenho de animais alimentados com pastagens tropicais do gênero Panicum e Brachiaria no Rio Grande do Sul, ainda são escassos. Todavia, é comum a utilização de forrageiras como capim-elefante (Pennisetum purpureum Schum.), papuã (Brachiaria plantaginea (Link) Hitchc), sorgo (Sorghum bicolor (L.) Moench) e milheto (Pennisetum americanum (L.) Leeke).

Nestas espécies forrageiras geralmente a categoria mais utilizada em sistema de pastejo são animais em recria (ALMEIDA et al., 2000; HERINGER \& MOOJEN, 2002; LEITE, 2006), pois as pastagens tropicais são opções para suprir com maior eficiência as exigências dos animais no período de primavera e verão, estabelecendo melhores condições para o crescimento de categorias mais exigentes, como a de animais jovens (MÍSSIO et al.; 2006).

Assim, o objetivo desta revisão bibliográfica será discutir algumas formas de manejo e utilização das principais espécies tropicais utilizadas no Rio Grande do Sul para a produção de bovinos de corte.

\section{Dinâmica de espécies tropicais no Sul do Brasil}

O Rio Grande do Sul, durante o verão, é marcado por elevados períodos de estiagem o que proporciona nos campos sulinos uma elevada redução da taxa de acúmulo ( $\mathrm{kg} \mathrm{MS/dia)} \mathrm{e} \mathrm{consequentemente} \mathrm{na} \mathrm{massa} \mathrm{de} \mathrm{forragem}$ ( $\mathrm{kg} / \mathrm{ha}$ de MS). Contudo, a implantação de espécies tropicais resistentes à seca, surge como uma alternativa para eliminar o vazio forrageiro apresentado 
OSMARI, M.P. et al. Produção de bovinos de corte em pastagem de estação quente no Sul do Brasil - uma revisão. PUBVET, Londrina, V. 5, N. 22, Ed. 169, Art. 1140, 2011.

durante esse período, principalmente, em anos de déficit hídrico mais acentuado.

Quando trabalhamos com espécies tropicais e que apresentam crescimento ereto, devemos considerar a carga animal como uma das formas de manejo.

Baixas pressões de pastejo favorecem a elongação e espessamento dos caules, propiciando além de um menor tempo entre o estádio vegetativo e o reprodutivo, representado pela emissão de inflorescências, uma maior probabilidade de perda dessa forragem, ou por subutilização ou por tombamento à medida que os animais avançam para pastejarem.

No entanto, quando existe uma elevada carga animal, há a tendência de uma maior produção de perfilhos, que são estimulados por fatores hormonais, favorecido pelo pastejo, ou até mesmo pela redução das temperaturas noturnas, como verificado no sorgo. Mas, pela constante apreensão das forragens, pode haver uma redução da proporção de folhas, que são as porções vegetativas, reduzindo as taxas fotossintéticas e acelerarando o processo de senescência, além é claro, de permitir um maior aparecimento de porções descobertas de solo, em decorrência do constante pisoteio.

Segundo Langer (1972) gramíneas forrageiras são plantas adaptadas ao pastejo por apresentarem contínua emissão de folhas logo após a desfolhação, pois durante a fase vegetativa, a zona meristemática se encontra próxima ao nível do solo e, portanto, longe do alcance dos animais. Ainda, se alguns meristemas forem removidos, estes rapidamente serão repostos pelo aparecimento de novos perfilhos.

Para que o período de utilização da pastagem seja maior e que proporcione um bom desempenho animal, é necessário boas práticas de manejo. Para isso alguns autores têm utilizado a manipulação da pastagem em diferentes alturas (CECATO et al., 2001; CANO et al., 2004) ou diferentes ofertas de lâminas foliares verdes (BARBOSA et al., 2006; MACHADO et al., 2007). 
No entanto no Rio Grande do Sul, os pesquisadores tem se detido à trabalhos envolvendo produção forrageira e animal em pastagens tropicais submetidas a diferentes doses de nitrogênio (LANÇANOVA et al., 1988; MARTINS et al., 2000; HERINGER \& MOOJEN, 2002), diferentes tipos de adubos (NEUMANN et al., 2005) e com o uso de suplementação (ROCHA et al., 2004; SANTOS et al., 2005; LEITE, 2006; ROMAN et al., 2008).

Com o constante avanço de espécies tropicais do gênero Brachiaria e Panicum no sul do Brasil, espera-se que pesquisas utilizando diferentes ofertas ou alturas de dossel como manejo sejam utilizadas, a fim de uma melhor compreensão da dinâmica destas pastagens em um ambiente que apresenta condições climáticas diferentes de seus habitat de origem.

\subsection{Características do capim-elefante}

O capim-elefante (Pennisetum purpureum Schum.) é uma planta forrageira largamente difundida e utilizada para formação de capineiras. Tendo em vista seu hábito de crescimento, caracterizado por rápido alongamento do colmo, adapta-se melhor ao pastejo rotacionado (SILVA et al., 1994).

De acordo com Restle et al. (2002), por ser uma espécie perene, apresenta crescimento primaveril, preenche o vazio forrageiro existente entre o período de utilização das pastagens anuais de estação fria e anuais de estação quente. No entanto, Menezes et al. (2008) comentam que se utilizada como a única fonte alimentar para bezerros, o capim elefante deve ser associado à suplementação alimentar, pois o ganho de peso é baixo.

Míssio et al. (2006) comentam que o capim-elefante tem conquistado os pecuaristas pela alta produção de matéria seca/ha, elevados ganhos de peso vivo/ha e por suportar elevada carga animal.

No que se refere ao comportamento forrageiro, Almeida et al. (2000) verificaram que à medida que a oferta de forragem ( $\mathrm{kg}$ de matéria seca (MS) de lâminas verdes $/ 100 \mathrm{~kg}$ de peso vivo (PV)/dia) do capim-elefante anão 'Mott' diminuía de 16 para $4 \mathrm{~kg}$ MS/100 kg de PV, a redução na massa de forragem levava à maior participação de outras espécies na pastagem, redução na 
OSMARI, M.P. et al. Produção de bovinos de corte em pastagem de estação quente no Sul do Brasil - uma revisão. PUBVET, Londrina, V. 5, N. 22, Ed. 169, Art. 1140, 2011.

produção de afilhos, diminuição da biomassa radicular, diminuição na porosidade e aumento na densidade aparente do solo, direcionando à menor produção de MS/ha/dia.

No entanto, o aumento da massa de forragem proporcionou reduções dos teores de proteína bruta (PB) devido ao acúmulo de material senescente, em decorrência da subutilização da pastagem e permitiu o controle de plantas invasoras (ALMEIDA et al., 2000), principalmente pelo sufocamento proporcionado nas espécies indesejáveis. Este manejo trata-se um de controle que é importante para evitar a degradação da pastagem e com isso novos gastos com a renovação desta (MENEZES et al.; 2008).

Ao se trabalhar com baixas ofertas de forragem de lâminas verdes, que é o principal órgão de interceptação da radiação solar para produção de fotossintatos (SOLLENBERGER et al., 2005), pode haver degradação da pastagem, pela constante apreensão do alimento pelos animais.

Em contrapartida, Silva et al. (1994) observaram que a oferta de forragem entre $12-9 \mathrm{~kg} \mathrm{MS} / 100 \mathrm{~kg}$ de PV resultou em subutilização da forragem produzida, devido, principalmente, a elevadas taxas e acúmulos diários, associado a elevados resíduos de massa de forragem e a baixa carga animal necessária para a utilização da oferta de forragem citada.

Desta forma, a recria de bovinos em capim-elefante seria mais eficiente quando fosse utilizada uma massa intermediária de lâminas foliares $(1.925 \mathrm{~kg}$ de MS de massa de lâminas foliares/ha) (MÍSSIO et al.; 2006). Este manejo é importante, pois evita a degradação da pastagem e do solo pela ausência de matéria orgânica e aumento de proporções de solo descoberto, bem como evita que haja a perda de massa de forragem por subutilização, onde o excedente de pasto senesce diminuindo sua utilização para a produção animal.

A utilização de espécies de crescimento ereto com altura de dossel reduzidas, a fim de evitar a elongação e o espessamento do caule e a implantação de cultivares forrageiras com elevada produção de perfilhos, podem favorecer uma maior produção de folhas e, consequentemente, um melhor aproveitamento da pastagem, com melhor desempenho animal. 


\subsection{Características do capim-papuã}

Considerado uma planta invasora nas culturas de verão, a Brachiaria planaginea, conhecida comumente pelo nome de capim papuã ou capim marmelada, é uma espécie anual de hábito decumbente. Apresenta elevada produção de massa verde/ha, com boas características qualitativas (MARTINS et al., 2000), o que o torna altamente promissor como forrageira, principalmente em áreas com rotação de lavoura e pecuária.

Para Guasso et al. (2011) o crescimento das áreas de lavouras de verão no Rio Grande do Sul proporcionou o aumento de áreas infestadas de papuã, o que devido a grande produção de sementes e persistência no solo por vários anos, permitiu ser reconhecida como a invasora mais importante. No entanto, quando o pastejo é devidamente manipulado pode ser uma ferramenta econômica e ecológica para a redução da população de gramíneas invasoras, reduzindo os custos com insumos.

Martins et al. (2000) trabalhando com níveis crescentes de nitrogênio em pastagem de capim papuã, verificaram que esta espécie responde satisfatoriamente à adubação nitrogenada, aumentando os teores de PB, digestibilidade 'in vitro' da matéria orgânica (DIVMO) e participação percentual do capim na pastagem, à medida que a adubação aumentava.

Osmari (2010) verificou teores de PB diminuindo de 18,42 para $11,14 \%$ à medida que a oferta de forragem aumentava de 5,1 para $12,5 \mathrm{~kg}$ de MS/100 $\mathrm{kg}$ de PV. O mesmo comportamento decrescente foi verificado para a DIVMO (74,40 para $68,90 \%)$.

Aita (1995) trabalhando com diferentes pastagens de estação quente na recria de bovinos de corte, verificou que grandes períodos sem pastejo favoreceram o desenvolvimento do papuã, mas impediu sua melhor utilização, pois em pastejo mais intenso pode levar a uma perda de qualidade e a grandes perdas de forragem pelo pisoteio. No entanto, ofertas de forragem de $14 \mathrm{~kg}$ MS/100 kg de PV, podem causar acúmulo de material de baixo valor nutritivo, favorecido por maiores taxas de senescência. 


\subsection{Características do sorgo}

O sorgo é uma planta de metabolismo $\mathrm{C} 4$, de dia curto e com altas taxas fotossintéticas. A planta de sorgo tolera mais o déficit de água e o excesso de umidade no solo do que a maioria dos outros cereais e pode ser cultivado em uma ampla faixa de condições de solo (MAGALHÃES et al., 2003), principalmente, pelo fato de apresentar em sua estrutura altos teores de lignina, o que dificulta a perda de água em ambientes quentes.

A alta capacidade de perfilhamento é considerada sua principal característica e é influenciada pelo grau de dominância apical, que é regulado por fatores hormonais, ambientais e genéticos (MAGALHÃES et al., 2003).

Trabalhos de pesquisa na região sul do país utilizando sorgo como base forrageira são escassos, principalmente pela sua dificuldade de manejo. Todavia, a maioria dos trabalhos publicados utilizam a massa de lâminas foliares como ponto de partida para um bom manejo forrageiro.

Sollenberger et al. (2005) aconselham que o controle de sua massa de forragem em pastejo seja realizado em função de suas porções foliares, visto que é o componente do manejo que permite predizer com segurança o desempenho animal, por integrar a massa de lâminas foliares com a taxa de lotação.

Aita (1995) comenta que de um modo geral, há concordância dos autores citados que o melhor manejo do sorgo em pastejo está na utilização de oferta de forragem ( $\mathrm{kg} \mathrm{MS} / 100 \mathrm{~kg} \mathrm{PV}$ ) próxima de 10\%, o que condiciona uma massa de forragem próximos a $2000-2500 \mathrm{~kg} / \mathrm{MS} / \mathrm{ha}$, corroborando com Restle et al. (2002).

No entanto, Osmari (2010) sugere uma oferta de forragem entre 7,5 e 9,0 kg MS de lâminas foliares/100 kg de PV para uma boa resposta forrageira e um bom desempenho animal.

Ao trabalhar com sorgo em pastejo interrompido, Leite (2006) obteve massa de forragem média de $6.837,10 \mathrm{~kg}$ de MS/ha e a carga animal (CA) de $3.753,55 \mathrm{~kg}$ de PV/ha, valores superiores aos obtidos por Restle et al. (2002), utilizarando pastejo contínuo. 
Aita (1995) e Restle et al. (2002) observaram que com o passar do tempo de utilização da pastagem, sua digestibilidade e PB tendem a diminuir, devido ao aumento de material senescente, o que de certa forma, acontece com qualquer gramínea utilizada.

Tomich et al. (2006) avaliaram híbridos de sorgo com capim-sudão em comparação a outros volumosos utilizados em períodos de baixa disponibilidade forrageira e verificaram que o nível de PB para os híbridos de sorgo avaliados foi, em média, de 14,5\%, representando uma superioridade de $75 \%$ em relação aos níveis de PB dos outros volumosos avaliados, que variaram de 1,3 a 8,2\%. Para estes autores, esses níveis de 14,5\% de PB poderiam reduzir a necessidade de suplementação protéica na forma de concentrados, e conseqüentemente, diminuir os custos com alimentação dos animais.

Osmari (2010) verificou valores médios de $18,20 \%$ de PB para as folhas de sorgo manejado sob diferentes ofertas de lâminas foliares, sendo que à medida que a oferta aumentava, os teores deste nutriente diminuíam, o mesmo verificado para os nutrientes digestíveis totais e DIVMO. De qualquer forma, o menor valor encontrado para a PB foi de $15,24 \%$ para a oferta de $12,5 \mathrm{~kg}$ de MS de lâminas foliares/100 kg de PV, sendo superior aos verificados por Tomich et al. (2006).

\subsection{Características do milheto}

O milheto é uma gramínea anual de verão, originada do Sub-Saara africano (MAMAN et al., 2000). Apresenta crescimento ereto, excelente produção de perfilhos e vigoroso rebrote após cortes ou pastejos (MELO, 2006).

Segundo Guimarães et al. (2005), o milheto é uma gramínea que apresenta grande potencial forrageiro, pelo seu alto valor nutritivo e sua grande versatilidade de utilização. Na produção de sistemas intensivos a cultura do milheto vem sendo muito utilizada por suas características de alta 
OSMARI, M.P. et al. Produção de bovinos de corte em pastagem de estação quente no Sul do Brasil - uma revisão. PUBVET, Londrina, V. 5, N. 22, Ed. 169, Art. 1140, 2011.

produção e boa qualidade alcançadas nos períodos mais quentes do ano (HERINGER \& MOOJEN, 2002).

De acordo com Guasso et al. (2011) o milheto é a gramínea anual de verão mais utilizada para pastejo no Rio Grande do Sul. Como alternativa de manejo, pode-se utilizar uma massa de forragem baixa no início de sua utilização, com a finalidade de permitir melhor perfilhamento e evitar o alongamento precoce de seus colmos (ROMAN et al., 2008).

Melo (2006) avaliando o milheto e o sorgo sob diferentes níveis de água no solo, observaram que o estresse hídrico severo durante todo o período de crescimento, afeta o rendimento de forragem das culturas, além de diminuir os teores de fibra das espécies, mesmo elas sendo indicadas na literatura como plantas que se adaptam bem às condições de suprimento limitado de água.

Alguns autores assemelham a qualidade forrageira do milheto ao sorgo. Aita (1995) e Restle et al. (2002) verificaram similaridade entre a massa de forragem média, os teores de PB e digestibilidade 'in vitro' da matéria seca (DIVMS) para estas espécies.

Aita (1995) também cita que o melhor manejo do milheto está na utilização de ofertas de forragem próximas a $10 \%$, condicionando resíduos próximos a 2000-2500 kg/MS/ha, o mesmo observado por Roman et al. (2008).

Mesmo quando utilizado no final do verão e início do outono, Roman et al. (2008) verificaram que a produção de forragem do milheto foi maior que a produção do campo nativo em toda sua estação de crescimento, demonstrando o potencial forrageiro desta espécie anual.

\section{Desempenho animal em pastagens tropicais}

Almeida et al. (2000) trabalhando com diferentes ofertas de lâminas foliares de capim-elefante anão 'Mott' observaram maior ganho médio diário (GMD) $(1,042 \mathrm{~kg})$ quando a oferta de forragem foi de $10,02 \mathrm{~kg} \mathrm{MS} / 100 \mathrm{~kg}$ de PV. No entanto, quando utilizaram ofertas de forragem superiores $(14,7 \mathrm{~kg}$ 
OSMARI, M.P. et al. Produção de bovinos de corte em pastagem de estação quente no Sul do Brasil - uma revisão. PUBVET, Londrina, V. 5, N. 22, Ed. 169, Art. 1140, 2011.

MS/100 kg de PV), conseqüentemente com maior massa de forragem, observaram diminuição do GMD.

Quando a massa de forragem é muito elevada, o novo crescimento é igual ao material que senesce e morre, prejudicando a qualidade do material a ser consumido pelos animais, embora permita a seleção do material a ser ingerido (ALMEIDA et al., 2000).

O melhor peso final verificado por Míssio et al. (2006) foi observado com disponibilidade de $1.925 \mathrm{~kg}$ MS de lâminas foliares/ha, em que os animais atingiram $234,5 \mathrm{~kg}$ de peso vivo médio e um GMD de $0,635 \mathrm{~kg}$, consumindo capim-elefante. No entanto, os animais não apresentaram deposição de gordura satisfatórios em decorrência do baixo período de pastejo (63 dias).

No entanto, Martins et al. (2000) quando trabalharam com adubação nitrogenada em capim papuã, observaram que a oferta de $14,41 \mathrm{~kg} \mathrm{MS} / 100 \mathrm{~kg}$ do PV dificultou a coleta uniforme das amostras, o que poderia ter influenciado nos dados obtidos. Assim, ofertas muito baixas ou muito altas, influenciam a estrutura da forragem de tal modo que prejudica a sua utilização, bem como o desempenho dos animais em pastejo.

Aita (1995) e Restle et al. (2002) trabalhando com papuã na recria de bovinos de corte observaram um GMD de 1,054 kg, sendo superiores ao obtido por Martins et al. (2000) $(0,85 \mathrm{~kg} / \mathrm{animal} / \mathrm{dia})$. No entanto Martins et al. (2000) consideram que estes ganhos de peso vivo (GPV) são satisfatórios quando comparados com os GPV obtidos em outras espécies anuais de verão e que podem ser atribuídos à elevada disponibilidade de forragem utilizada (14 $\mathrm{kg} \mathrm{MS/100} \mathrm{kg} \mathrm{de} \mathrm{PV),} \mathrm{o} \mathrm{que} \mathrm{causou} \mathrm{acúmulo} \mathrm{de} \mathrm{material} \mathrm{de} \mathrm{baixo} \mathrm{valor}$ nutritivo.

Ao utilizarem várias espécies de estação quente na recria de novilhos de corte, Restle et al. (2002) verificaram que GMD obtido para milheto e sorgo foram superiores ao do capim-elefante (Tabela 1).

Os maiores GMD encontrados para estas espécies (Tabela 1) correspondem aos maiores valores de PB e DIVMS obtidos nas avaliações das pastagens, evidenciando que o desempenho animal é reflexo da qualidade da 
OSMARI, M.P. et al. Produção de bovinos de corte em pastagem de estação quente no Sul do Brasil - uma revisão. PUBVET, Londrina, V. 5, N. 22, Ed. 169, Art. 1140, 2011.

forragem ingerida, desde que a disponibilidade de forragem não seja fator limitante para consumo.

Segundo Restle et al. (2002) a massa de forragem disponível para sorgo e milheto ( $2.039 \times 2.260 \mathrm{~kg} \mathrm{MS} /$ ha, respectivamente) permitiu que os animais selecionassem uma dieta adequada em qualidade e quantidade, favorecendo melhores GMD (Tabela 1).

Tabela 1 - Massa de forragem ( $\mathrm{kg} \mathrm{MS/ha),} \mathrm{teor} \mathrm{de} \mathrm{proteína} \mathrm{bruta} \mathrm{( \% ),} \mathrm{digestibilidade}$ 'in vitro' da matéria seca (\%), ganho de peso médio diário (GMD) $(\mathrm{kg})$ e ganho de peso vivo (GPV) (kg/ha) em diferentes pastagens de estação quente

\begin{tabular}{|c|c|c|c|c|c|c|}
\hline \multirow{2}{*}{ Pastagens } & \multicolumn{5}{|c|}{ Períodos } & \multirow{2}{*}{ Média } \\
\hline & 1 & 2 & 3 & 4 & 5 & \\
\hline \multicolumn{7}{|c|}{ Massa de forragem total } \\
\hline Capim-elefante & 3428 & 2874 & 3595 & 4108 & 4126 & 3626 \\
\hline Papuã & - & 2200 & 2788 & 3281 & 2864 & 2783 \\
\hline Sorgo & - & 1408 & 2260 & 2230 & 2258 & 2039 \\
\hline Milheto & - & 2200 & 2850 & 2068 & 1921 & 2260 \\
\hline \multicolumn{7}{|c|}{ Proteína Bruta* } \\
\hline Capim-elefante & 5,60 & 5,35 & 6,15 & 5,60 & 4,45 & 5,43 \\
\hline Papuã & - & 11,70 & 10,15 & 9,30 & 9,15 & 10,08 \\
\hline Sorgo & - & 12,75 & 10,05 & 8,50 & 8,50 & 9,95 \\
\hline Milheto & - & 13,30 & 9,35 & 9,65 & 10,00 & 10,58 \\
\hline \multicolumn{7}{|c|}{ DIVMS* } \\
\hline Capim-elefante & 57,85 & 51,45 & 50,75 & 48,35 & 46,25 & 50,93 \\
\hline Papuã & - & 68,30 & 59,00 & 49,40 & 46,70 & 55,85 \\
\hline Sorgo & - & 67,50 & 55,90 & 48,55 & 46,30 & 54,56 \\
\hline Milheto & - & 68,55 & 56,75 & 48,50 & 45,45 & 54,81 \\
\hline \multicolumn{7}{|c|}{ GMD } \\
\hline Capim-elefante & 0,605 & 1,103 & 1,098 & 1,036 & 0,835 & $0,928^{b}$ \\
\hline Papuã & - & 1,107 & 1,178 & 0,996 & 0,911 & $1,054^{\mathrm{ab}}$ \\
\hline Sorgo & - & 1,295 & 1,330 & 1,112 & 0,370 & $1,121^{a}$ \\
\hline Milheto & - & 1,353 & 1,205 & 1,138 & 0,920 & $1,188^{\mathrm{a}}$ \\
\hline \multicolumn{6}{|c|}{ GPV } & Total \\
\hline Capim-elefante & 259,0 & 139,9 & 139,5 & 130,9 & 105,1 & 774,4 \\
\hline Papuã & - & 118,5 & 315,6 & 154,8 & 79,6 & 668,5 \\
\hline Sorgo & - & 190,2 & 199,4 & 158,9 & 21,8 & 570,3 \\
\hline Milheto & - & 178,0 & 242,3 & 156,1 & 63,5 & 639,9 \\
\hline
\end{tabular}


OSMARI, M.P. et al. Produção de bovinos de corte em pastagem de estação quente no Sul do Brasil - uma revisão. PUBVET, Londrina, V. 5, N. 22, Ed. 169, Art. 1140, 2011.

Aita (1995) também não encontrou diferença no GMD entre milheto e sorgo, mas sugeriu que o menor GMD observado no sorgo pode ter sido em virtude da maior participação de colmo na pastagem em relação às folhas.

Osmari (2010) ao utilizar vacas de descarte em pastejo contínuo de sorgo manejado sob diferentes ofertas de lâminas foliares verificou GMD de 0,$730 ; 0,930 ; 0,940$ e $0,960 \mathrm{~kg}$ para as ofertas de 5,$1 ; 7,0 ; 9,5$ e $12,5 \mathrm{~kg}$ de MS de lâminas foliares $/ 100 \mathrm{~kg}$ de PV, respectivamente. A maior oferta de forragem favoreceu a elongação dos colmos de sorgo, o que permitiu rápido aparecimento de inflorescências e grande perda de material pastejável por pisoteio à medida que os animais avançavam dentro dos piquetes de utilização. No entanto a menor oferta de forragem proporcionou aumento da área de solo descoberto e favoreceu o aparecimento de espécies invasoras e não pastejáveis.

Quando analisaram o GPV ( $\mathrm{kg} / \mathrm{ha}$ ) Restle et al. (2002) encontraram superioridade do capim-elefante $(774,4 \mathrm{~kg} / \mathrm{ha})$ em relação ao papuã, sorgo e milheto (668,5; 570,3 e 639,9, respectivamente). Essa superioridade ocorreu em função de o capim-elefante ser uma espécie perene, o que proporcionou maior período de utilização, enquanto o menor ganho de peso verificado na pastagem de sorgo se deve, principalmente, ao baixo GMD obtido no último período (Tabela 1) e à tendência de menores cargas suportadas pela pastagem. Ainda, o maior GPV/ha do capim-elefante pode ser sido reflexo da elevada massa de forragem (3.626 kg MS/ha) e do satisfatório teor de PB observado nas folhas $(10,19 \%)$.

Martins et al. (2000) encontraram GPV de 208,62; 297,36 e 354,46 $\mathrm{kg} / \mathrm{ha}$ para as doses de 0; 100 e $200 \mathrm{~kg} / \mathrm{ha}$ de $\mathrm{N}$ ao trabalhar com papuã, sendo inferiores aos relatados por Restle et al. (2002). Mesmo assim, o autor concluiu que a pastagem de papuã responde satisfatoriamente à adubação nitrogenada, além de apresentar elevado potencial de produção de forragem e animal, concordado com Aita (1995).

Ao trabalhar com comportamento ingestivo de novilhas em pastejo de milheto e papuã, Guasso et al. (2011) verificaram que o desempenho, 
OSMARI, M.P. et al. Produção de bovinos de corte em pastagem de estação quente no Sul do Brasil - uma revisão. PUBVET, Londrina, V. 5, N. 22, Ed. 169, Art. 1140, 2011.

comportamento ingestivo, ingestão de forragem e ingestão de nutrientes digestíveis totais obtidos com o capim papuã foram semelhantes aos verificados com o milheto, o que torna hábil a utilização do papuã na produção de bovinos de corte em áreas infestadas com esta gramínea.

Com o avanço do período de utilização de pastagens tropicais há uma tendência à redução da participação de folhas, que é a principal parte consumida pelos animais, em detrimento a elongação dos colmos e ao surgimento de porções em senescência (MENEZES et al., 2008; OSMARI, 2010). Desta forma, a antecipação da utilização destas pastagens poderia maximizar os resultados a serem obtidos, com maior período de utilização e melhores GMD.

Quando o objetivo é a recria de categorias mais exigentes, como novilhas, há o aumento da dependência do uso de pastagens de alta qualidade quando alimentadas em sistemas intensivos. Desta forma, pode ser necessário a utilização de suplementos energéticos, associados às pastagens, assegurando um crescimento corporal mais rápido e prenhez em sistemas de acasalamento de 14 ou 18 meses de idade (SANTOS et al., 2005).

Menezes et al. (2008) trabalhando com suplementações energéticas em pastagem de capim-elefante verificaram que o fornecimento de casca de soja, farelo de arroz, grão de milho ou até mesmo a mistura múltipla desses alimentos a $1 \%$ do $\mathrm{PV}$, proporciona desempenho indicado para sistemas de abate e acasalamento entre 18 a 24 meses de idade. Para Santos et al. (2005) a polpa cítrica e a casca de soja podem substituir o grão de milho como suplemento energético para a recria de novilhas de corte.

Santos et al. (2005) avaliaram o desempenho animal de fêmeas em recria com suplementação energética em pastagens anuais de milheto (Tabela 2) e verificaram que o comportamento no GMD foi em decorrência da relação folha/colmo que apresentou comportamento linear decrescente (Tabela $3)$. 
OSMARI, M.P. et al. Produção de bovinos de corte em pastagem de estação quente no Sul do Brasil - uma revisão. PUBVET, Londrina, V. 5, N. 22, Ed. 169, Art. 1140, 2011.

As mudanças na estrutura da pastagem afetam o tamanho do bocado, que por sua vez, é positivamente correlacionado com o consumo de MS, representado pelo consumo da relação folha/colmo das plantas.

Tabela 2 - Médias de ganho de peso médio diário (GMD), peso vivo (PV) e escore de condição corporal (ECC) das novilhas, por tratamento e período

\begin{tabular}{|c|c|c|c|c|}
\hline \multirow[b]{2}{*}{ Tratamento } & & Período & & \multirow[b]{2}{*}{ Média } \\
\hline & $\begin{array}{c}16 / 02 / 01 \text { a } \\
08 / 03 / 01\end{array}$ & $\begin{array}{c}\text { 09/03/01 a } \\
30 / 03 / 01\end{array}$ & $\begin{array}{c}31 / 03 / 01 \text { a } \\
21 / 04 / 01\end{array}$ & \\
\hline \multicolumn{5}{|c|}{ GMD } \\
\hline Past & 0,655 & $0,696^{b}$ & $-0,223^{b}$ & $0,376^{b}$ \\
\hline Past/M & 0,667 & $1,024^{a}$ & $0,141^{a}$ & $0,611^{a}$ \\
\hline Past/P & 0,619 & $1,101^{a}$ & $0,125^{a}$ & $0,615^{a}$ \\
\hline \multicolumn{5}{|c|}{ PV (kg) } \\
\hline Past & 109,3 & $123,9^{b}$ & $119,2^{b}$ & 117,4 \\
\hline Past/M & 109,5 & $131,0^{a}$ & $134,0^{a}$ & 124,8 \\
\hline Past/P & 108,5 & $131,6^{a}$ & $134,2^{a}$ & 124,7 \\
\hline \multicolumn{5}{|c|}{$\operatorname{ECC}(1-5)^{*}$} \\
\hline Past & 2,70 & $2,74^{b}$ & $2,65^{b}$ & $2,70^{b}$ \\
\hline Past/M & 2,85 & $2,83^{a b}$ & $2,85^{a}$ & $2,84^{a}$ \\
\hline Past/P & 2,83 & $2,98^{a}$ & $2,90^{a}$ & $2,90^{a}$ \\
\hline
\end{tabular}

Past: pastagem de milheto; Past/M: pastagem de milheto + suplementação de milho moído; Past/P: pastagem de milheto + suplemento de polpa cítrica.

* ECC = escore de condição corporal: 1- muito magro e 5- muito gordo.

$a, b$ Letras diferentes na mesma coluna diferem entre si pelo teste de Tukey a $5 \%$ de significância.

Fonte: Santos et al. (2005)

No primeiro período de avaliação, quando a proporção de folhas verdes da pastagem esteve acima de $70 \%$ em todos os tratamentos (Tabela 3), o fornecimento de suplementos não interferiu no desempenho individual dos animais (Tabela 2). Com o avanço do ciclo do milheto e significativo decréscimo na relação folha/colmo, provavelmente as novilhas não conseguiram obter exclusivamente da forragem um aporte satisfatório de nutrientes (SANTOS et al., 2005). 
OSMARI, M.P. et al. Produção de bovinos de corte em pastagem de estação quente no Sul do Brasil - uma revisão. PUBVET, Londrina, V. 5, N. 22, Ed. 169, Art. 1140, 2011.

Tabela 3- Proporção lâmina foliar/colmo (\%) e relação lâmina foliar/colmo, por período de avaliação, tratamento e médias, em pastagem de milheto sob pastejo contínuo de novilhas de corte

\begin{tabular}{lcccc}
\hline Tratamento & $16 / 02$ a 08/03 & $09 / 03$ a 30/03 & $31 / 03$ a 21/04 & Média \\
\hline PAST & $79 / 21(3,7)$ & $43 / 57(0,8)$ & $41 / 59(0,7)$ & $54 / 46(1,2)$ \\
PAST/M & $75 / 25(3,0)$ & $51 / 49(1,0)$ & $30 / 70(0,4)$ & $52 / 48(1,1)$ \\
PAST/P & $87 / 13(6,6)$ & $60 / 40(1,5)$ & $40 / 60(0,7)$ & $62 / 38(1,6)$ \\
\hline Média & $80 / 20(4,0)^{\text {a }}$ & $51 / 49(1,0)^{\mathrm{b}}$ & $37 / 63(0,3)^{\mathrm{c}}$ & $56 / 44(1,6)$ \\
\hline
\end{tabular}

Past: pastagem de milheto; Past/M: pastagem de milheto + suplementação de milho moído; Past/P: pastagem de milheto + suplemento de polpa cítrica.

$a, b$ Letras diferentes na mesma linha diferem entre si pelo teste de Tukey a $5 \%$ de significância.

Fonte: Santos et al. (2005)

A baixa densidade de forragem e elevada dispersão espacial de folhas de pastagens tropicais podem dificultar o processo de ingestão pelos animais, em função do aumento no tempo necessário à formação do bocado. Nesta situação, os animais não-suplementados foram os mais prejudicados e, com isso, o GDM dos submetidos à pastejo + suplementação de milho (PAST/M) e ao pastejo + suplementação com polpa cítrica (PAST/P) $(0,613 \mathrm{~kg})$, que não diferiram entre $\mathrm{si}$, foi $63 \%$ superior ao obtido em pastagem semsuplementação (PAST) (0,376 kg) (Tabela 2) (SANTOS et al., 2005).

Santos et al. (2005) observaram que o GMD das fêmeas exclusivamente em pastagem de milheto, embora esta seja uma forragem de alta qualidade, foi muito inferior aos demais tratamentos, o que seria fundamental para o acasalamento das novilhas aos 14 meses (Tabela 2).

No entanto, Roman et al. (2008) comenta que o uso de suplementação energética em pastagens de alto valor nutritivo, é uma forma de garantir melhor balanceamento da dieta e aumentar o consumo de MS, com incremento no desempenho individual e na capacidade de suporte das pastagens.

A resposta dos animais em pastejo à suplementação pode variar com as características da pastagem, com o manejo adotado (PILAU et al., 2005) ou o ciclo da planta (PILAU et al., 2004). Além disso, a suplementação pode 
OSMARI, M.P. et al. Produção de bovinos de corte em pastagem de estação quente no Sul do Brasil - uma revisão. PUBVET, Londrina, V. 5, N. 22, Ed. 169, Art. 1140, 2011.

influenciar o comportamento ingestivo, mesmo sem interferir nos tempos de ruminação e ócio (BREMM et al., 2005), a seletividade dos animais e as características da pastagem. Em contrapartida, Roman et al. (2008) não verificaram influência da suplementação nas características produtivas e estruturais do milheto em pastejo.

As melhores taxas de ganho de peso verificadas nos animais suplementados permitiram que as novilhas chegassem ao outono com PV e escore de condição corporal (ECC) superiores aos animais mantidos exclusivamente em pastagem (Tabela 2). Assim, concluíram que a suplementação energética em pastagem de milheto é uma alternativa viável para as novilhas no período inicial pós-desmama, garantindo um bom desempenho individual, além de um desenvolvimento satisfatório para o primeiro serviço das novilhas aos 18 ou 24 meses (SANTOS et al., 2005), o mesmo observado por Menezes et al. (2008).

Todavia, quando o objetivo é o acasalamento de novilhas de corte aos 18/20 meses de idade, a utilização exclusiva de pastagem natural no verão/outono após o primeiro inverno é insuficiente para assegurar desenvolvimento adequado a estes animais (ROCHA et al., 2004).

Rocha et al. (2004) observaram 0,814 kg de GMD para novilhas em pastagem de milheto, sendo superiores aos trabalhos já mencionados. Foi verificado, que estas novilhas aos 20 meses apresentaram ECC superiores aos animais provenientes dos sistemas com campo nativo, embora tenham sido inferiores a 3,0 pontos. Este ECC de 3,0 pontos é considerado desejável para novilhas de reposição, no período entre os três meses de idade e o acasalamento, sendo um dos indicadores do estado nutricional que mais se associa com a percentagem de prenhez.

De acordo com Roman et al. (2008), no início do pastejo a quantidade de lâminas foliares presentes no milheto permitiu aos animais colherem quantidade suficiente de nutrientes, garantindo aos animais sem suplementação apresentarem desempenho similar aos que receberam suplementação, indicando efeito substitutivo - do consumo de pasto por 
consumo de suplemento. Já a partir do segundo período experimental, a modificação estrutural do dossel, com redução da quantidade de lâminas foliares, não permitiu que fosse obtido, exclusivamente do pasto o aporte necessário de nutrientes, apesar da manutenção da qualidade da dieta colhida (SANTOS et al., 2005).

No pastejo de forrageiras tropicais maduras, a seletividade animal pode ser superada pela limitação na capacidade de ingestão, em razão da menor quantidade de MS apreendida e, conseqüentemente, do baixo consumo de nutrientes digestíveis por unidade de tempo. Nesse caso, a utilização de suplemento pode promover desempenho superior, fornecendo aporte adicional de nutrientes, os quais não foram colhidos em quantidade suficiente quando as bezerras permaneceram exclusivamente a pasto (SANTOS et al., 2005).

\section{Conclusões}

A utilização de pastagens tropicais para a recria de bovinos de corte é uma alternativa que possibilita bons GMD, auxiliando o desenvolvimento desta categoria animal, a qual possui maior exigência nutricional, podendo tornar a terminação mais rápida.

É importante um bom manejo das pastagens, como adequação de carga animal, pois influi na pressão de pastejo e, conseqüentemente, na oferta de forragem, o que permitirá a maior e melhor utilização forrageira.

Manejos que proporcionem maior proporção de folhas em relação aos colmos, por um período de utilização maior, são válidos, pois além de serem as porções consumidas pelos animais, apresentam maiores teores de PB e DIVMS, o que proporciona maiores GMD.

A recria de fêmeas de corte exclusivamente em pastagem de milheto pode comprometer o desenvolvimento corporal e reprodutivo das futuras matrizes, devido ao baixo GMD para esta categoria, sendo necessário o uso de suplementação. 
OSMARI, M.P. et al. Produção de bovinos de corte em pastagem de estação quente no Sul do Brasil - uma revisão. PUBVET, Londrina, V. 5, N. 22, Ed. 169, Art. 1140, 2011.

Na terminação de vacas de descarte a utilização exclusiva de pastagens tropicais associadas a um bom manejo e com boas qualidades nutricionais podem ser suficientes para permitir o satisfatório desempenho dos animais.

\section{Referências Bibliográficas}

AITA, V. Utilização de diferentes pastagens de estação quente na recria de bovinos de corte. Santa Maria, 1995. 102 f. Dissertação (Mestrado em Zootecnia) - Curso de PósGraduação em Zootecnia, Universidade Federal de Santa Maria.

ALMEIDA, E.X.; MARASCHIN, G.E.; HARTHMANN, O.E.L. et al. Oferta de forragem de capimelefante anão 'Mott' e o rendimento animal. Revista Brasileira de Zootecnia, v.29, n.5, p.1288-1295, 2000.

BARBOSA, M.A.A.F.; NASCIMENTO JUNIOR, D.; CECATO, U. Dinâmica da pastagem e desempenho de novilhos em pastagem de capim-tanzânia sob diferentes ofertas de forragem. Revista Brasileira de Zootecnia, v.35, n.4, p.1594-1600, 2006 (Suplemento).

BREMM, C.; ROCHA, M.G.; RESTLE, J. et al. Efeito de níveis de suplementação sobre o comportamento ingestivo de bezerras em pastagem de aveia (Avena strigosa Schreb) e azevém (Lolium multiflorum Lam.). Revista Brasileira de Zootecnia, v.34, n.2, p.319329, 2005.

CANO, C.C.P.; CECATO, U.; CANTO, M.W. et al. Produção de forragem do capim-tanzânia (Panicum maximum Jacq. cv. Tanzânia-1) pastejado em diferentes alturas. Revista Brasileira de Zootecnia, v.33, n.6, p.1949-1958, 2004 (Suplemento 2).

CECATO, U.; CASTRO, C.R.C.; CANTO, M.W. et al. Perdas de forragem em capim-tanzânia (Panicum maximumJacq. cv. Tanzânia-1) manejada em diferentes alturas sob pastejo. Revista Brasileira Zootecnia, v.30, p.295-301, 2001

GUASSO, V.C.; ROCHA, M.G.; PÖTTER, L. et al. Comportamento de pastejo e ingestão de forragem por novilhas de corte em pastagens de milheto e papuã. Revista Brasileira de Zootecnia, v.40, n.2, p.251-259, 2011.

GUIMARÃES JR.; GONÇALVES, L.C.; RODRIGUES, J.A.S. et al. Matéria seca, proteína bruta, nitrogênio amoniacal e pH das silagens de três genótipos de milheto (Pennisetum glaucum (L). R. Br.) em diferentes períodos de fermentação. Revista Brasileira de Milho e Sorgo, v.4, n. 2, p. 251-258, 2005.

HERINGER, I. \& MOOJEN, E.L. Potencial Produtivo, Alterações da Estrutura e Qualidade da Pastagem de Milheto Submetida a Diferentes Níveis de Nitrogênio. Revista Brasileira de Zootecnia, v.31, n.2, p.875-882, 2002 (suplemento).

LANÇANOVA, J.A.C.; RESTLE, J.; SANTOS, G.L. Produção e qualidade do capim papuã (Brachiaria plantaginea) sob efeito de freqüências de corte e nitrogênio. Ciência Rural, v.18, n.3, p.343-354, 1988.

LANGER, R.H.M. How grasses grow. London. 1972. 60p (Studies in Biology, 34). 
LEITE, D.T. Farelo de glúten de milho e farelo de arroz desengordurado na suplementação de bovinos de corte. Santa Maria, 2006. 74 f. Dissertação (Mestrado em Zootecnia) - Curso de Pós-Graduação em Zootecnia, Universidade Federal de Santa Maria.

MACHADO, L.A.Z.; FABRÍCIO, A.C.; ASSIS, P.G.G. et al. Estrutura do dossel em pastagens de capim-marandu submetidas a quatro ofertas de lâminas foliares. Pesquisa Agropecuária Brasileira, v.42, n.10, p.1495-1501, 2007.

MAGALHÃES, P.C.; DURÃES, F.O.M.; RODRIGUES, J.A.S. Fisiologia da Planta de Sorgo. Comunicado Técnico 86, ISSN 1679-0162 Novembro, Sete Lagoas, MG, 2003.

MAMAM, N. et al. Influence of variety and management level on pearl millet production in Niger: I. Grain yield and dry matter accumulation. African Crop Science Journal, v. 8, n.1, p. 25-34, 2000.

MARTINS, J.D.; RESTLE, J.; BARRETO, I.L. Produção animal em capim papuã (Brachiaria plantaginea (Link) Hitchc) submetido a níveis de nitrogênio. Ciência Rural, v.30, n.5, p.887-892, 2000.

MELO, D. Avaliação de sorgo (Sorghum bicolor L. Moench) e milheto (Pennisetum glaucum (L.) B. R.) sob diferentes níveis de água no solo. Patos, 2006. 59f. Dissertação (Mestrado em Zootecnia) - Curso de Pós-Graduação em Zootecnia, Universidade Federal de Campina Grande.

MENEZES, L.F.G.; RESTLE, J.; PASCOAL, L.L. et al. Fontes energéticas para suplementação de bezerros desmamados precocemente, mantidos em pastagem de capim-elefante (Pennisetum purpureum, SCHUM.). Ciência Animal Brasileira, v.9, n.1., p.30-42, janeiro/março, 2008.

MÍSSIO, R.L.; BRONDANI, I.L.; MENEZES, L.F.G. et al. Massas de lâminas foliares nas características produtivas e qualitativas da pastagem de capim-elefante "Pennisetum purpureum, Schum" (cv. "Taiwan") e desempenho animal. Ciência Rural, v.36, n.4, 1243-1248, 2006.

NEUMANN, M.; RESTLE, J.; ALVES FILHO, D.C. et al. Qualidade de forragem e desempenho animal em pastagem de sorgo (Sorghum bicolor, L.), fertilizada com dois tipos de adubo, sob pastejo contínuo. Revista Brasileira de Agrociência, v.11, n.2, p.221-226, 2005.

OSMARI, M.P. Dinâmica da pastagem de sorgo em diferentes ofertas de lâminas foliares na terminação de vacas de descarte. Santa Maria, 2010. 117f. Dissertação (Mestrado em Zootecnia) - Curso de Pós-Graduação em Zootecnia, Universidade Federal de Santa Maria.

PILAU, A.; ROCHA, M.G.; RESTLE, J. et al. Recria de novilhas de corte com diferentes níveis de suplementação energética em pastagem de aveia preta e azevém. Revista Brasileira de Zootecnia, v.33, n.6, p.2104-2113, 2004 (Suplemento 2).

PILAU, A.; ROCHA, M.G.; RESTLE, J. et al. Desenvolvimento de novilhas de corte recebendo ou não suplementação energética em pastagem com diferentes disponibilidades de forragem. Revista Brasileira de Zootecnia, v.34, n.5, p.1486-1492, 2005.

RESTLE, J.; ROSO, C; AITA, V. et al. Produção animal em pastagem com gramíneas de estação quente. Revista Brasileira de Zootecnia, v.31, n.3, p.1491-1500, 2002. 
ROCHA, M.G.; PILAU, A.; SANTOS, D.T. et al. Desenvolvimento de novilhas de corte submetidas a diferentes sistemas alimentares. Revista Brasileira de Zootecnia, v.33, n.6, p.2123-2131, 2004 (Suplemento 2).

ROMAN, J.; ROCHA, M.G.; GENRO, T.C.M. et al. Características produtivas e estruturais do milheto e sua relação com o ganho de peso de bezerras sob suplementação alimentar. Revista Brasileira de Zootecnia, v.37, n.2, p.205-211, 2008.

SANTOS, D.T., ROCHA, M.G.; QUADROS, F.L.F. et al. Suplementos energéticos para a recria de novilhas de corte em pastagens anuais. Desempenho animal. Revista Brasileira de Zootecnia, v.34, n.1, p.209-219, 2005.

SILVA, D.S.; GOMIDE, J.A; FONTES, C.A.A. et al. Pressão de pastejo em pastagem de capimelefante anão (Penisetum purpureum, Schum cv. Mott) 1- efeito sobre a estrutura e disponibilidade de pasto. Revista Brasileira de Zootecnia, v.23, n.2, p.249-257, 1994.

SOLLENBERGER, L.E.; MOORE, J.E.; ALLEN, V.G. et al. Reporting forage allowance in grazing experiments. Crop Science, v.45, p.896-900, 2005.

TOMICH, T. R.; Tomich, R.G.P.; Gonçalves, L.C. et al. Valor nutricional de híbridos de sorgo com capim-sudão em comparação ao de outros volumosos utilizados no período de baixa disponibilidade das pastagens. Arquivo Brasileiro de Medicina Veterinária e Zootecnia, v. 58, n. 6, p. 1249-1252, 2006. 